\title{
Wireless Torque Pulsations Measurement System for PMSMs
}

\author{
Maria Martinez, Daniel Fernandez, David Reigosa, Juan Manuel Guerrero and Fernando Briz \\ Dept. of Elect., Computer \& System Engineering, University of Oviedo, Gijón, Spain \\ martinezgmaria@uniovi.es, fernandezalodaniel@uniovi.es,diazdavid@uniovi.es, guerrero@uniovi.es, \\ fernando@isa.uniovi.es
}

\begin{abstract}
Torque pulsations are one of the major concerns in permanent magnet synchronous machines (PMSMs) operation. Torque pulsations can be mitigated by proper machine design and/or by control. Independently of the means being used, precise measurement of torque pulsation is highly desirable for the validation and improvement of machine designs and control strategies. This paper proposes a non-invasive, wireless vibration measurement system aimed to provide precise estimates of torque pulsations. The system is mounted on the rotor shaft of the PMSM, without including any mechanical coupling, providing on-line torque pulsation measurement and without interfering with the normal operation of the machine. The proposed concept has been validated experimentally. ${ }^{1}$
\end{abstract}

Keywords-Permanent Magnet Synchronous Machines, Torque vibrations, Cogging Torque, Torque Ripple.

\section{INTRODUCTION}

Permanent magnet synchronous machines (PMSMs) provide high efficiency, high power density and good dynamic response compared to other types of electrical machines [1]-[4]. These features have made PMSMs widely used in a large variety of high performance applications such as automotive, robotics, servo drive, military, aerospace, etc... [5]-[8].

One of the major concerns in PMSMs operation are torque pulsations (smooth torque production) [9]-[13]. Torque pulsations in PMSM result from: a) interaction between PMs and the stator slot opening, i.e. cogging torque; b) non-sinusoidal distribution of the stator windings, non-sinusoidal current waveform or nonsinusoidal back-EMF [9]-[13], i.e. electromagnetic torque ripple. Reduction of torque pulsations is always desirable; its minimization can be critical in some applications [6]. Mechanical torque pulsations can be mitigated by proper machine design, methods that have been proposed for this include dummy slots [15], [18], stator slots skewing [15], the use of factional number of slots per pole [25], magnet shifting [25] or magnet magnetization shaping [16].

1 This work was supported in part by the Research, Technological Development and Innovation of the Spanish Ministry Economy and Competitiveness, under grant MINECO-17-ENE2016-80047-R and by Thyssenkrupp under grant CAT-003-17.
Unfortunately, torque pulsations are intrinsic to the production of average torque, meaning that it cannot be fully eliminated. In addition to machine design, strategies based on feedforward compensation or harmonic decoupling using proper control strategies have been proposed for torque pulsation reduction [11], [17]. Implementation of these methods can be difficult and required a significant commissioning effort, as they require precise measurement of the torque pulsations (e.g. magnitude and phase angle of each relevant frequency component), which will vary in general as a function of machine operating condition.

Precise measurement of torque pulsations of PMSMs under different operating conditions (torque and speed, magnet temperature, ...) is highly desirable for multiple purposes, including assessment and validation of new machine designs, assessment/optimization of control strategies aimed to reduced torque pulsations or fault detection (e.g. demagnetization) in existing machines. Existing torque pulsation measurement systems include: conventional rotary torque transducers based on strain gauges [20], [22]-[23], Ferraris sensor [19], piezoelectric accelerometers [19], acceleration estimation using rotary encoder [19] and a weight variation of a beam attached to the rotor [21]. However, all existing methods show some limitation. Rotary torque transducers are the most popular option [20]; however, these sensors are relatively bulky, and can introduce resonances into the system, which could hide the actual vibration produced by the machine [22]. In addition, they must be scaled to measure the average torque, what can seriously compromise their resolution measuring torque pulsations, their limited bandwidth and high cost being often further concerns [20], [23]. A beam attached to the rotor was proposed in [21]; its use being limited to zero speed [21], measuring in the whole speedtorque map not being possible. Systems based on a Ferraris sensor, a rotary encoder system or a piezoelectric accelerometer [19] overcome the bandwidth limitation of rotary torque transducers and can measure torque pulsations with high resolution. However, all these systems present limitations in the low speed range, e.g. resonances that make them unreliable in low-speed ranges.

This paper presents a wireless, shaft-mounted torque pulsation measurement system. The system is mainly intended for the assessment/optimization of machine 
designs and control strategies aimed to provide smooth torque, i.e. to reduce torque pulsations. Further potential uses would include fault or different types of degradation detection. Strengths of the proposed system are: high bandwidth; high resolution; lack of mechanical couplings, avoiding therefore the risk of resonances; operation in the whole speed range; no interfering with the normal operation of the machine. The system measures the torque pulsations independently of the average torque. The requirements for the system have been determined first from finite element analysis (FEA) of a PMSM, its performance being assessed from FEA and experimental data joint analysis. Though the paper will focus on its use with PMSMs, the system can be applied to other types of rotating machines suffering from torque pulsations.

The paper is organized as follows: the physics of torque pulsations in PMSMs are discussed in section II; FEA are presented in section III; details of the torque pulsations measurement system are presented in section IV; experimental results and its comparative with FEA results are shown in section V; Finally, conclusions are presented in section VII.

\section{AVERAge AND PUlsating TORQUe In PMSMs}

Physical behind torque pulsations in PMSMs is analyzed in this section. The fundamental model of a PMSM expressed in the synchronous rotor reference frame is described by (1), where $v_{d s}^{r}, v_{q s}^{r}, i_{d s}^{r}$ and $i_{q s}^{r}$ are the $d$ and $q$-axis stator voltages and currents in the rotor reference frame, $R_{d}, R_{q}, L_{d}$ and $L_{q}$ are the $d$ and $q$-axis resistances and inductances respectively, $\omega_{r}$ is the rotor speed, $\lambda_{p m}$ is the PM flux and $p$ is the differential operator. The output torque can be expressed by (2), where $P$ is the number of poles.

$$
\begin{aligned}
{\left[\begin{array}{c}
v_{d s}^{r} \\
v_{q s}^{r}
\end{array}\right]=} & {\left[\begin{array}{cc}
R_{d} & 0 \\
0 & R_{q}
\end{array}\right]\left[\begin{array}{l}
i_{d s}^{r} \\
i_{q s}^{r}
\end{array}\right]+p\left[\begin{array}{cc}
L_{d} & 0 \\
0 & L_{q}
\end{array}\right]\left[\begin{array}{l}
i_{d s}^{r} \\
i_{q s}^{r}
\end{array}\right]+} \\
& +\left[\begin{array}{cc}
0 & -\omega_{r} L_{q} \\
\omega_{r} L_{d} & 0
\end{array}\right]\left[\begin{array}{c}
i_{d s}^{r} \\
i_{q s}^{r}
\end{array}\right]+\left[\begin{array}{c}
0 \\
\lambda_{p m} \omega_{r}
\end{array}\right] \\
T_{\text {out }}= & \frac{3}{2} \frac{P}{2}\left[\lambda_{p m} i_{q s}^{r}+\left(L_{d}-L_{q}\right) i_{q s}^{r} i_{d s}^{r}\right]+T_{c o g} \\
= & T_{s y n}+T_{r e l}+T_{c o g}
\end{aligned}
$$

Assuming an ideal behavior of a PMSM (i.e. sinusoidal PM magnetic field, sinusoidal distributed winding, constant magnetic air-gap field in the axial direction), the output torque, (2), can be decomposed into synchronous/ electromagnetic torque $\left(T_{\text {syn }}\right)$, reluctance torque $\left(T_{\text {red }}\right)$ and cogging torque $\left(T_{c o g}\right)$. The torque equation (2) can be further developed (3)-(5) [2], where $\phi$ is the magnetic flux density, $\mathfrak{R}$ is the air-gap reluctance, $N$ is the number of stator coils and $\theta_{r}$ is the rotor angular position.

The term in (3), $T_{s y n}$, is the electromagnetic/ synchronous torque. In an ideal case (purely sinusoidal back-EMF and stator currents), it will be constant, i.e. without any torque ripple. However, non-sinusoidal backEMF and/or stator currents intrinsic to real machine designs will induce torque pulsations. Non-sinusoidal back-emf result from either non-sinusoidal PM magnetic field or nonsinusoidal distribution of the stator windings; stator currents are not sinusoidal due to the non-ideal behavior of the inverter feeding the machine. Both back-EMF and stator currents are half-wave symmetric, meaning that the resulting torque harmonics will consist of odd order harmonic components. For the particular case of threephase machines, torque harmonic components occur at six times the fundamental electrical frequency, $T_{s y n}$ being of the form shown (6) [2], where $T_{0}$ is the average synchronous torque, $T_{6 n}$ and $\phi_{6 n}$ are the magnitude and phase angle of the $\mathrm{n} \cdot 6^{\text {th }}$ harmonic component of the torque with $n$ being an integer number and $\omega_{e}$ the electrical excitation frequency. Harmonic components in (6) are commonly referred as torque ripple.

$$
\begin{gathered}
T_{\text {syn }}=N i \frac{d \phi}{d \theta_{r}} \\
T_{r e l}=\frac{1}{2} i^{2} \frac{d L_{d q}}{d \theta_{r}} \\
T_{\text {cog }}=-\frac{1}{2} \phi^{2} \frac{d \Re}{d \theta_{r}} \\
T_{\text {syn }}=T_{0}+T_{\text {ripple }}=T_{0}+\sum_{n=1}^{\inf } T_{6 n} \cdot \cos \left(n 6 \omega_{e} t+\phi_{6 n}\right)
\end{gathered}
$$

The term in (4), $T_{\text {rel }}$, is the reluctance torque due to different $\mathrm{d}$ - and q-axis inductances.

Finally, the term in (5), $T_{c o g}$, is the cogging torque produced by the interaction among magnets and stator teeth which try to align the rotor PMs with the minimum reluctance path through the stator teeth. The harmonic order (number of periods) of cogging torque for a rotor revolution is given by (7), where LCM stands for the least common multiple between the number of stator slots and poles, and $\mathrm{Q}$ is the number of slots of the machine.

$$
N_{c o g}=\operatorname{LCM}(Q, P)
$$

The simplest mechanical model linking torque and acceleration of a PMSM can be expressed (8) [1], where $\omega_{r}$ is the angular acceleration, and $J$ and $b$ are the overall inertia and viscous friction respectively. Torque pulsations due to $T_{c o g}$ and $T_{\text {ripple }}$ result in angular accelerations, from which torque pulsations could be estimated.

$$
T_{\text {out }}=J \alpha_{r}+b \omega_{r}
$$

\section{Study of Torque Pulsations By MeAns of FEA}

Fig. 1 shows the schematic representation of the machine that will be used both for simulation and experimental verification, the parameters being shown in Table I. The machine is a 36s/6p IPMSM. Fig. 2a shows the output torque obtained by FEA, while Fig $2 b$ shows the corresponding FFT. As predicted by (6)-(7), the $18^{\text {th }}$ and $36^{\text {th }}$ are the most relevant torque harmonic order components. The LCM between the number of stator slots and rotor poles is 36 ; consequently, $T_{\text {cog }}$ will have a frequency equal to $36 \omega \mathrm{r}$ (7). Additionally, when fundamental current is applied, torque ripple will appear at 
integer multiples of 6 times the electrical frequency (6), i.e. $18 \omega r, 36 \omega r, \ldots$.

TABLE I. IPMSM PARAMETERS

\begin{tabular}{|l|l|l|l|l|l|l|}
\hline $\mathrm{P}_{\text {RATED }}$ & $\mathrm{V}_{\text {RATED }}$ & $\mathrm{I}_{\text {RATED }}$ & $\omega_{\mathrm{r}}$ & Poles & Slots & Magnet \\
\hline $7.5 \mathrm{~kW}$ & $350 \mathrm{~V}$ & $14 \mathrm{~A}$ & $1800 \mathrm{rpm}$ & 6 & 36 & $\mathrm{~N}-42 \mathrm{SH}$ \\
\hline
\end{tabular}

Fig. $3 \mathrm{a}$ and $\mathrm{b}$ shows the magnitude of the $18^{\text {th }}$ and $36^{\text {th }}$ torque harmonic components vs. $q$-axis current with $d$-axis current being $0 \mathrm{~A}$. Fig. $3 \mathrm{c}$ and $\mathrm{d}$ show analogous results when $d$-axis current is varying between $-1 \mathrm{pu}$ and $1 \mathrm{pu}$, and there is no q-axis current. It is concluded from Fig. 3a and $3 \mathrm{c}$ that the effect of $I_{d}$ on torque ripple $\left(18^{\text {th }}\right.$ harmonic component) is more relevant than $I_{q}$. Variation of $18^{\text {th }}$ harmonic component of the torque (i.e. torque ripple) with $I_{d}$ and $I_{q}$ is seen to be almost linear, torque ripple being zero when no current is being injected. On the contrary, the cogging torque $\left(36^{\text {th }}\right.$ torque harmonic component when $I_{d}=I_{q}=0$ ), see Fig. $3 \mathrm{~b}$ and $3 \mathrm{~d}$, is not zero when no current is being injected, its magnitude being significantly bigger than the $18^{\text {th }}$ harmonic component; i.e. the most relevant source of torque pulsation in this machine is the cogging torque.

\section{Shaft-Mounted TORQue PULSATION MEASUREMENT SYSTEM}

A torque ripple measurement system which overcomes the limitations of existing methods is presented in this section. The system can operate at any speed and load level, does not introduce resonances which could interfere with the measurements, provides high bandwidth and high accuracy, independently or the torque ripple to average torque ratio.

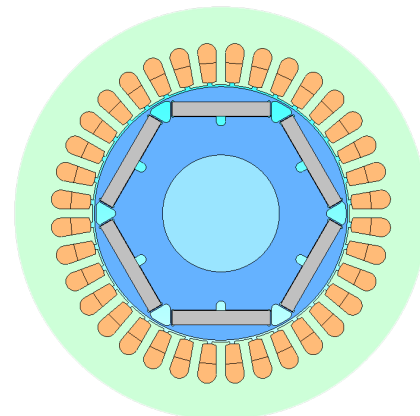

Fig. 1.- 36s/6p IPMSM design.
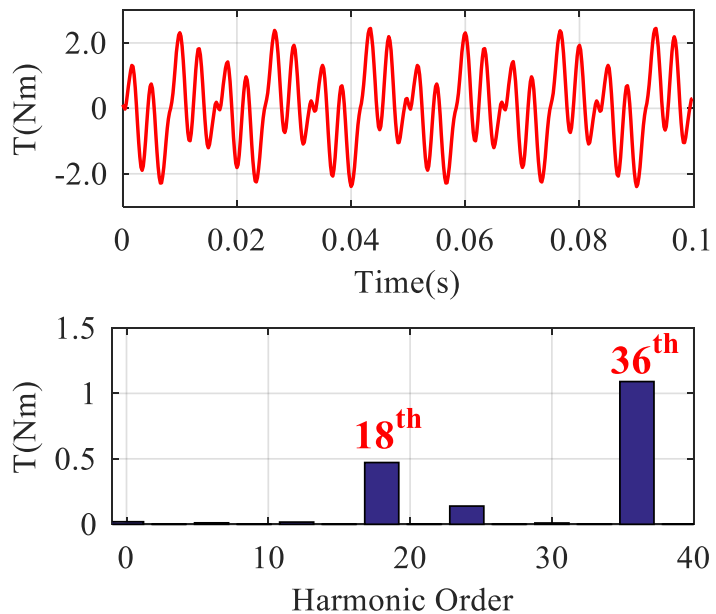

Fig. 2.- Simulation results. a) Electromagnetic torque of $36 \mathrm{~s} / 6 \mathrm{p}$ IPMSM and b) FFT. $\mathrm{I}_{\mathrm{d}}=-1 \mathrm{pu}, \omega_{r}=20 \mathrm{rad} / \mathrm{s}$.
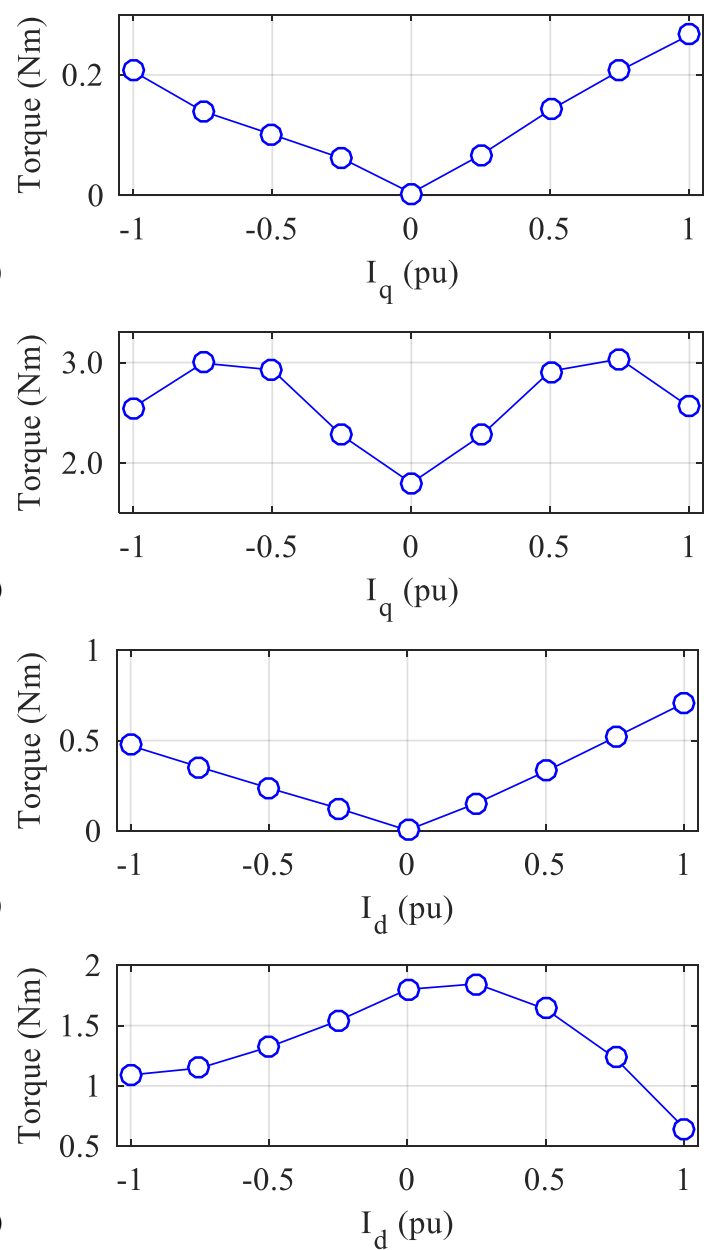

Fig. 3.- Simulation results. a) $18^{\text {th }}$, b) $36^{\text {th }}$ torque harmonic variation $v s I_{q}$ current with $I_{d}=0$ A. c) $18^{\text {th }}$, d) $36^{\text {th }}$ torque harmonic variation vs $I_{d}$ current. $\omega_{r}=20 \mathrm{rad} / \mathrm{s}$.

Table II. Main Characteristics of the Measurement System

\begin{tabular}{|l|l|}
\hline Resolution & $0.977 \mathrm{mg}$ \\
\hline Measurement range & $-8 \mathrm{~g}$ to $8 \mathrm{~g}$ \\
\hline Bandwidth & $3.30 \mathrm{kHz}$ \\
\hline Number of sensors & $1(3$-axis $)$ \\
\hline Output Noise & $126 \mu \mathrm{g} / \sqrt{\mathrm{Hz}}$ \\
\hline
\end{tabular}

The system is shown in Fig. 4, its main characteristics are shown in Table II. A schematic representation of the measurement system is shown in Fig. 5a; it includes a threeaxis digital accelerometer, $\mu$ Controller, battery and $\mathrm{Wi}-\mathrm{Fi}$ module. The three-axis digital accelerometer is attached to the rotor shaft as seen in Fig. 6. Torque pulsations appearing in the $\mathrm{x} / \mathrm{y}$-axis are the focus of this paper. Accelerometer signals are acquired by a $\mu$ Controller and transmitted using a Wi-Fi link to a central computer (see Fig. 5a). The maximum sampling rate of the system is 3.30 $\mathrm{kHz}$, a sampling rate of $1 \mathrm{kHz}$ was used for the experiments shown in this paper. To supply the three-axis digital accelerometer, $\mu$ Controller and wireless transmission device, a power stage composed of a Li-Po battery and DCDC converters, was included. Fig. 5b shows a screenshot of the desktop application that has been developed.

The signal provided by the accelerometer, $a$ (9) can be split into centripetal $a_{c}$ (x-axis) (10) and tangential $a_{t}$ (yaxis) acceleration (11) components (see Fig. 6 and 7). 
Centripetal acceleration is given by (10), being $r$ the distance between the sensor to the center of the shaft, $\omega_{r}$ the mechanical angular frequency, $g$ the Earth's gravity, $a_{c h}$ the magnitude of the $\mathrm{n}^{\text {th }}$ harmonic component of the centripetal acceleration, $h$ the harmonic order of the $h^{\text {th }}$ harmonic component and $\varphi_{c h}$ the phase of the $\mathrm{h}^{\text {th }}$ harmonic component of the centripetal acceleration. A general expression of the tangential acceleration, $a_{t}$, is given by (11), where $a_{t h}$ is the magnitude of the $h^{\text {th }}$ harmonic component of the tangential acceleration, $\varphi_{t h}$ is the phase of the $\mathrm{h}^{\text {th }}$ harmonic component of the tangential acceleration.

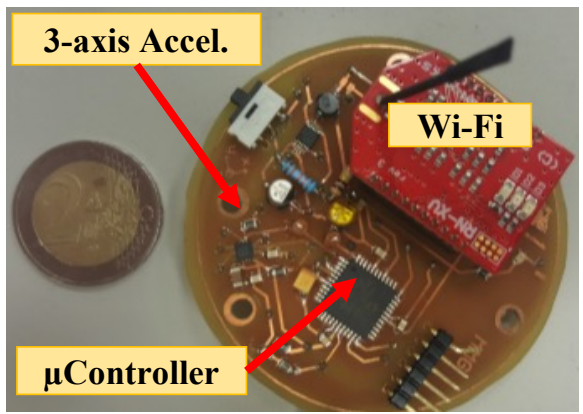

Fig. 4.- Experimental setup used for rotor acceleration measurement

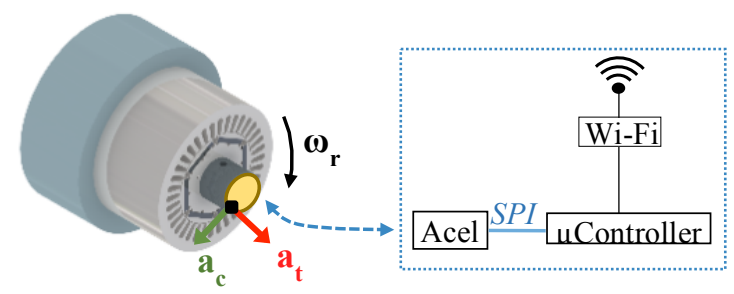

a)

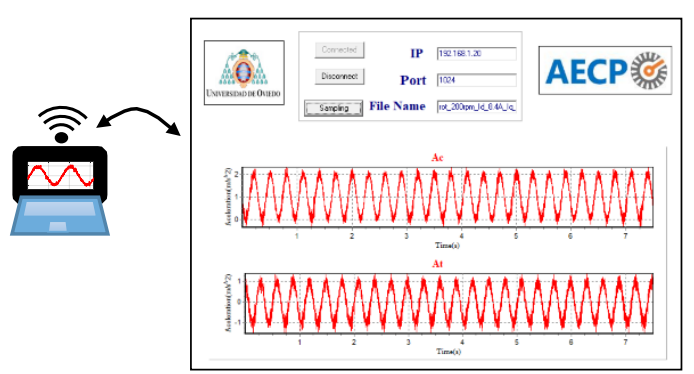

b)

Fig. 5.- (a) Schematic representation of the torque pulsation measurement system and (b) desktop application.

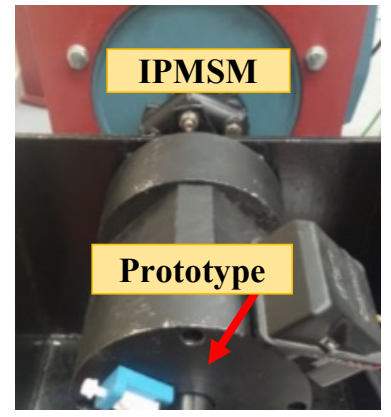

Fig. 6.- IPMSM with the wireless acceleration measurement system.

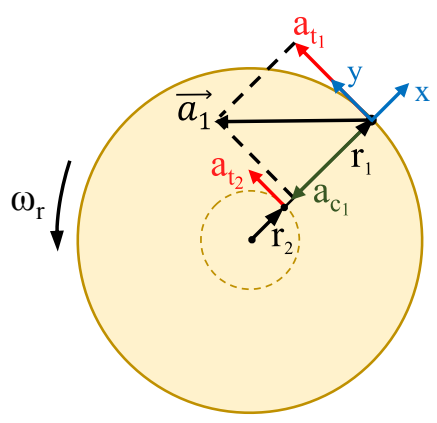

Fig. 7.- Decomposition of the acceleration vector of a rotating body.

$$
\begin{gathered}
\vec{a}=a_{c}+j a_{t} \\
a_{c}=r \omega_{r}^{2}+g \cos \left(\omega_{r} t\right)+\sum_{h=1}^{\inf } a_{c h} \cos \left(h \omega_{r} t+\varphi_{c h}\right) \\
a_{t}=g \sin \left(\omega_{r} t\right)+\sum_{h=1}^{\inf } a_{t h} \sin \left(h \omega_{r} t+\varphi_{t h}\right) \\
a_{t}^{\prime}=a_{t}-g \sin \left(\omega_{r} t\right)=\sum_{h=1}^{\inf } a_{t h} \sin \left(h \omega_{r} t+\varphi_{t h}\right) \\
a_{t}^{\prime}=r \alpha_{r} \\
T_{\text {out }}=J \alpha_{r}+b \omega_{r}=J \frac{a_{t}^{\prime}}{r}+b \omega_{r}
\end{gathered}
$$

The system has been mounted on a 36slot/6poles IPMSM, see Fig.1 and 6. Fig. 8a shows an example of $a_{t}$ measurement; Fig. 8b shows the corresponding FFT. It is observed from Fig. $8 \mathrm{~b}$ that there is a component in the tangential acceleration at $\omega_{r}$, which corresponds to the Earth's gravity, $g$ in (11), the rest of the harmonics (i.e. $6 \omega_{r}$, $\left.18 \omega_{r}, 30 \omega_{r}, 36 \omega_{r}, ..\right)$ being produced by torque pulsations of this particular machine. After decoupling Earth's gravity form the $y$-axis acceleration measurements (11), (12) is obtained, $a_{t}$; i.e. $a_{t}$ contains only accelerations resulting from torque pulsations. It can be observed from (13) that $a_{t}{ }^{\prime}$ is proportional to the distance of the accelerometer to the center of the shaft, $r$, and to the angular acceleration $\alpha_{r}$ (8) being also independent of the rotor speed.

\section{EXPERIMENTAL RESULTS}

Experimental results have been conducted using the IPMSM shown in Fig. 1 and 6. The test bench can be seen in Fig. 9. The IPMSM is equipped with the rotor acceleration measurement system shown in Fig. 4. Fig. 10 shows the $18^{\text {th }}$ and $36^{\text {th }}$ harmonics of the measured tangential rotor acceleration for the same working conditions as in Fig. 3. Harmonic components obtained by FEA shown in Fig. 3 are also included in Fig. 10 to ease the comparative analysis.

It can be also observed that there is a good agreement between the tangential experimentally measured acceleration and torque provided by FEA (i.e. the tangential acceleration, is proportional to the machine torque (14)), the exception being the $36^{\text {th }}$ harmonic component vs. Id current. 
a)
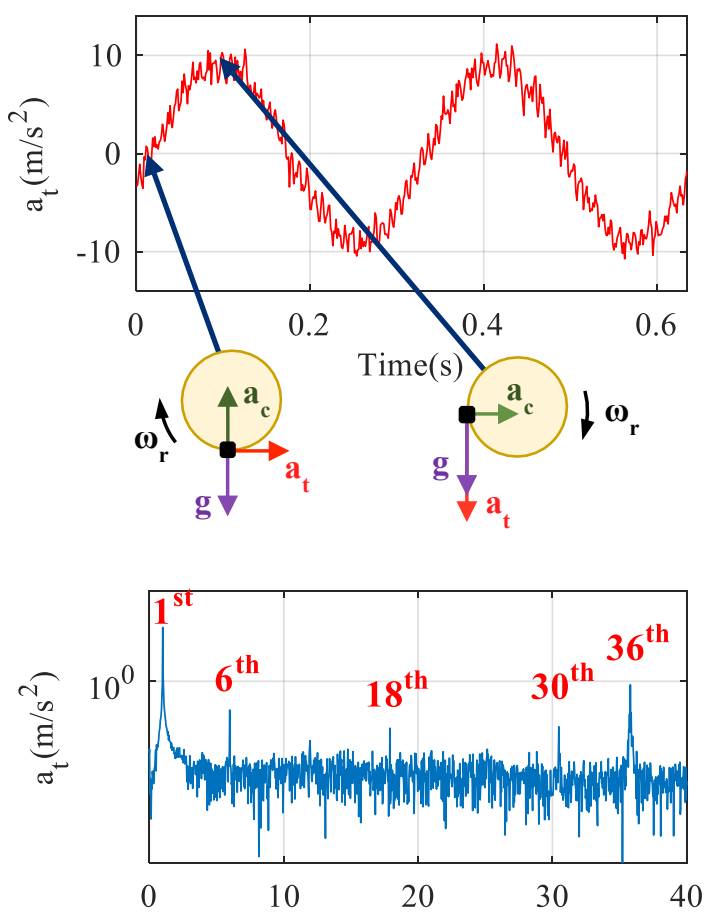

b)

Harmonic Order

Fig. 8.- a) Tangential acceleration $\left(a_{t}\right)$ measurement and b) FFT of $a_{t} . i_{d q}=0$; $\omega_{r}=20 \mathrm{rad} / \mathrm{s}$.

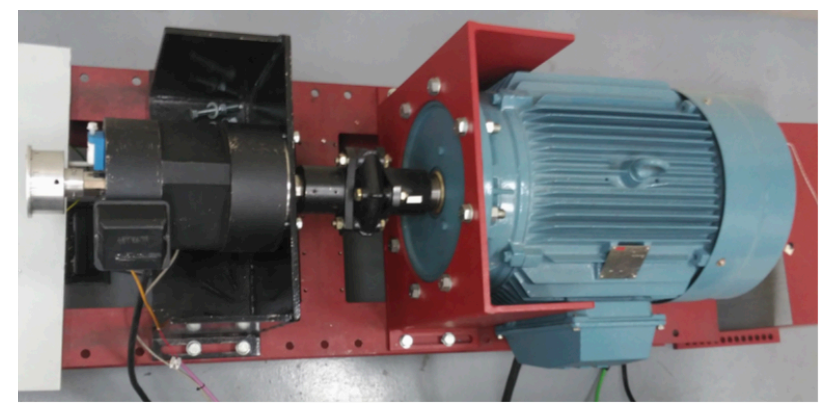

Fig. 9.- Picture of the test bench.

Fig. 11 shows $18^{\text {th }}$ and $36^{\text {th }}$ torque harmonic components vs. $I_{d}$ and for PM magnetization states of $100 \%$ and $95 \%$. It is observed that the $18^{\text {th }}$ torque harmonic component does not change significantly with the PM magnetization state, however the $36^{\text {th }}$ torque harmonic component varies substantially. It is observed that FEA results for a $95 \%$ magnetization fit better with the experimental results. This suggests that the magnetization state of the real machine could be lower than $100 \%$. It is noted however that there are other sources which could explain the deviations, e.g. mismatch of materials properties for the actual machine and FEA model, or assembling tolerances for the real machine. This is subject of ongoing research.

\section{CONCLUSIONS}

A shaft-mounted torque ripple measurement system has been presented in this paper. Analytical models and FEA have been used to determine the main characteristics of the torque pulsations, from which the requirements for the measurement system have been stablished. The system uses shaft-mounts 3D accelerometers, and can operate at any speed and load level, provides high bandwidth and high

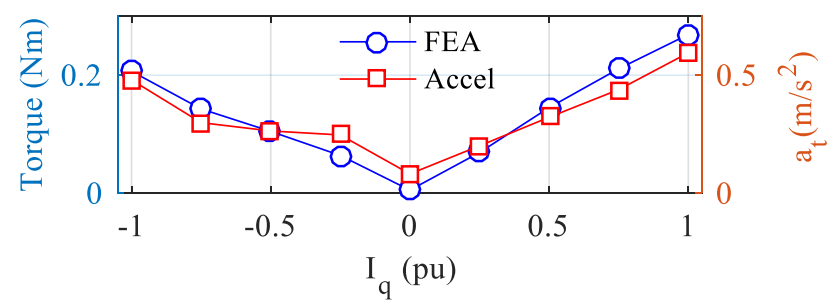

a)

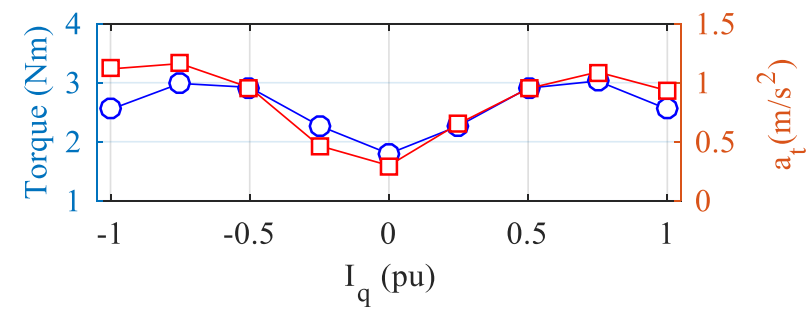

b)

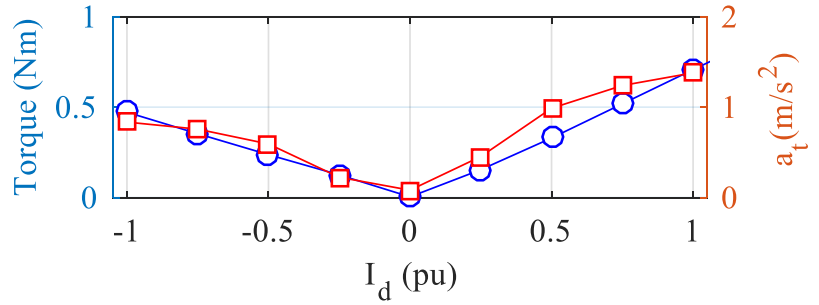

c)

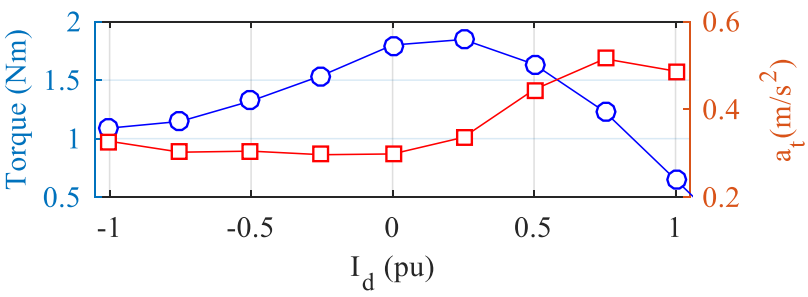

Fig. 10.- a) $18^{\text {th }}$, b) $36^{\text {th }}$ tangential acceleration harmonic components (experimental) and torque harmonic components (simulation) vs $I_{q}$ current; c) $18^{\text {th }}$, d) $36^{\text {th }}$ tangential acceleration harmonic components (experimental) and torque harmonic components (simulation) vs $I_{d}$ current. $\omega_{r}=20 \mathrm{rad} / \mathrm{s}$.

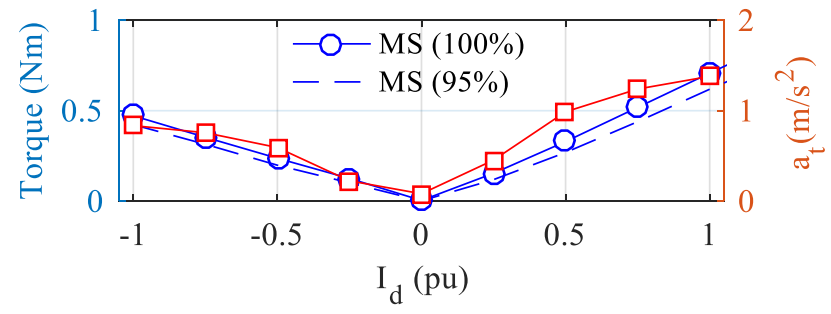

a)

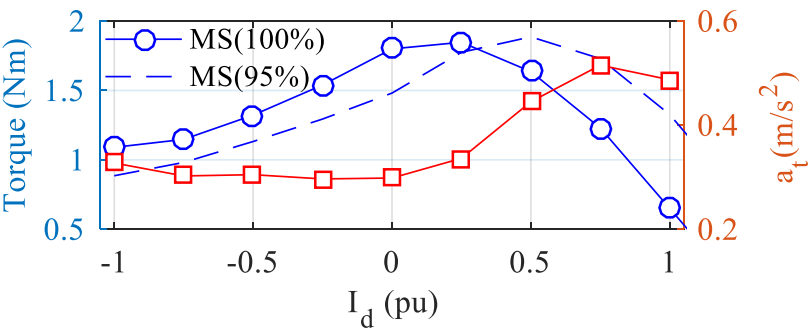

Fig. 11.- a) $18^{\text {th }}$, b) $36^{\text {th }}$ torque harmonic variation vs. $I_{d}$ for different magnetization states (simulation) and experimentally obtained tangential acceleration. $\omega_{r}=20 \mathrm{rad} / \mathrm{s}$.

accuracy, independently of the torque ripple to average torque ratio, and does not introduce resonances. Extensive experimental results have been provided to confirm the performance of the measurement system.

\section{REFERENCES}

[1] D. W. Novotny and T.A. Lipo, "Vector Control and Dynamics of AC Drives" Oxford Science Publications, 1996. 
[2] Duane C. Hanselman, "Brushless Permanent Magnet Motor Design" New York: Mc-Graw Hill, 1994.

[3] D. Reigosa, D. Fernandez, Y. Park, A. B. Diez, S. B. Lee and F. Briz, "Detection of demagnetization in permanent magnet synchronous machines using hall-effect sensors," IEEE Energy Conversion Congress and Exposition (ECCE), pp. 4686-4693, Oct. 2017

[4] D. Reigosa, D. Fernandez, C. Gonzalez, S. B. Lee and F. Briz, "Permanent magnet synchronous machine drive control using analog hall-effect sensors," IEEE Energy Conversion Congress and Exposition (ECCE), pp. 3966-3971, Oct. 2017.

[5] B. Saunders, G. Heins, F. De Boer and M. Thiele, "Cogging torque estimation for sensorless PMSM," International Conference on Electrical Machines (ICEM), 2949-2954, Sept. 2012.

[6] M. Piccoli, and M. Yim. "Cogging Torque Ripple Minimization via Position Based Characterization." Robotics: Science and Systems, 2014.

[7] O. Pyrhonen and P. Eskelinen, "Advanced measurement of rotor vibration in electric drives." IEEE Aerospace and Electronic Systems Magazine, vol.13, no. 5, pp. 21-23, May 1998.

[8] J. C. Urresty, R. Atashkhooei, J. R. Riba, L. Romeral and S. Royo, "Shaft Trajectory Analysis in a Partially Demagnetized PermanentMagnet Synchronous Motor." IEEE Transactions on Industrial Electronics, vol. 60, no. 8, pp. 3454-3461, Aug. 2013.

[9] Z. Azar, Z. Q. Zhu and G. Ombach, "Influence of Electric Loading and Magnetic Saturation on Cogging Torque, Back-EMF and Torque Ripple of PM Machines." IEEE Transactions on Magnetics, vol. 48, no. 10, pp. 2650-2658, Oct. 2012.

[10] X. Ge and Z. Q. Zhu, "Sensitivity of Manufacturing Tolerances on Cogging Torque in Interior Permanent Magnet Machines With Different Slot/Pole Number Combinations.” IEEE Transactions on Industry Applications, vol. 53, no. 4, pp. 3557-3567, July-Aug. 2017.

[11] S. Rojas, M. A. Pérez, J. Rodríguez and H. Zelaya, "Torque ripple modeling of a permanent magnet synchronous motor." IEEE International Conference on Industrial Technology (ICIT), pp. 433438, March 2010.

[12] D. H. Lee, C. L. Jeong and J. Hur, "Analysis of cogging torque and torque ripple according to unevenly magnetized permanent magnets pattern in PMSM." IEEE Energy Conversion Congress and Exposition (ECCE), pp. 2433-2438, Oct. 2017.

[13] H. Jussila, P. Salminen, M. Niemela, and J. Pyrhonen, "Guidelines for Designing Concentrated Winding Fractional Slot Permanent Magnet Machines.” International Conference on Power Engineering,
Energy and Electrical Drives (POWERENG), pp. 191-194, April 2007.

[14] L. Dosiek and P. Pillay, "Cogging Torque Reduction in Permanent Magnet Machines.” IEEE Transactions on Industry Applications, vol. 43, no. 6, pp. 1565-1571, Nov.-Dec. 2007.

[15] N. Bianchi and S. Bolognani, "Design techniques for reducing the cogging torque in surface-mounted PM motors" IEEE Transactions on Industry Applications, vol. 38, no. 5, pp. 1259-1265, Sep./Oct. 2002.

[16] C. Studer, A. Keyhani, T. Sebastian and S. K. Murthy, "Study of cogging torque in permanent magnet machines." IEEE Industry Applications Society Annual Meeting (IAS), pp. 42-49 vol.1, Oct. 1997.

[17] H. Le-Huy, R. Perret and R. Feuillet, "Minimization of Torque Ripple in Brushless DC Motor Drives." IEEE Transactions on Industry Applications, vol. 22, no. 4, pp. 748-755, July 1986.

[18] Z. Q. Zhu and D. Howe, "Influence of design parameters on cogging torque in permanent magnet machines." IEEE Transactions on Energy Conversion, vol. 15, no. 4, pp. 407-412, Dec 2000.

[19] A. Schramm, E. Sworowski and J. Roth-Stielow, "Methods for measuring torque ripples in electrical machines." IEEE International Electric Machines and Drives Conference (IEMDC), pp. 1-8, May 2017.

[20] http://www.interfacetorque.co.uk

[21] Zhu, Z. Q. "A simple method for measuring cogging torque in permanent magnet machines." IEEE Power \& Energy Society General Meeting (PES), pp. 1-4, July 2009.

[22] G. Heins, M. Thiele and T. Brown, "Accurate Torque Ripple Measurement for PMSM." IEEE Transactions on Instrumentation and Measurement, vol.60, no. 12, pp. 3868-3874, Dec. 2011.

[23] L. Ferraris, F. Franchini and E. Poskovic, "The cogging torque measurement through a new validated methodology." IEEE International Conference on Compatibility, Power Electronics and Power Engineering (CPE-POWERENG), pp. 398-403, April 2017

[24] G. Liu, X. Du, W. Zhao and Q. Chen, "Reduction of Torque Ripple in Inset Permanent Magnet Synchronous Motor by Magnets Shifting." IEEE Transactions on Magnetics, vol. 53, no. 2, pp. 1-13, Feb. 2017.

[25] L. Dosiek and P. Pillay, "Cogging Torque Reduction in Permanent Magnet Machines." IEEE Transactions on Industry Applications, vol. 43, no. 6, pp. 1565-1571, Nov.-Dec. 2007. 